\title{
Pulmonary Sequestration Supplied by the Right Coronary Artery
}

\author{
Deng-Wei Chou, Kuo-Mou Chung, Yeun Tarl Fresner Ng Jao and Ching-Chang Fang
}

Key words: pulmonary sequestration, right coronary artery

(Intern Med 53: 2553-2554, 2014)

(DOI: 10.2169/internalmedicine.53.2906)
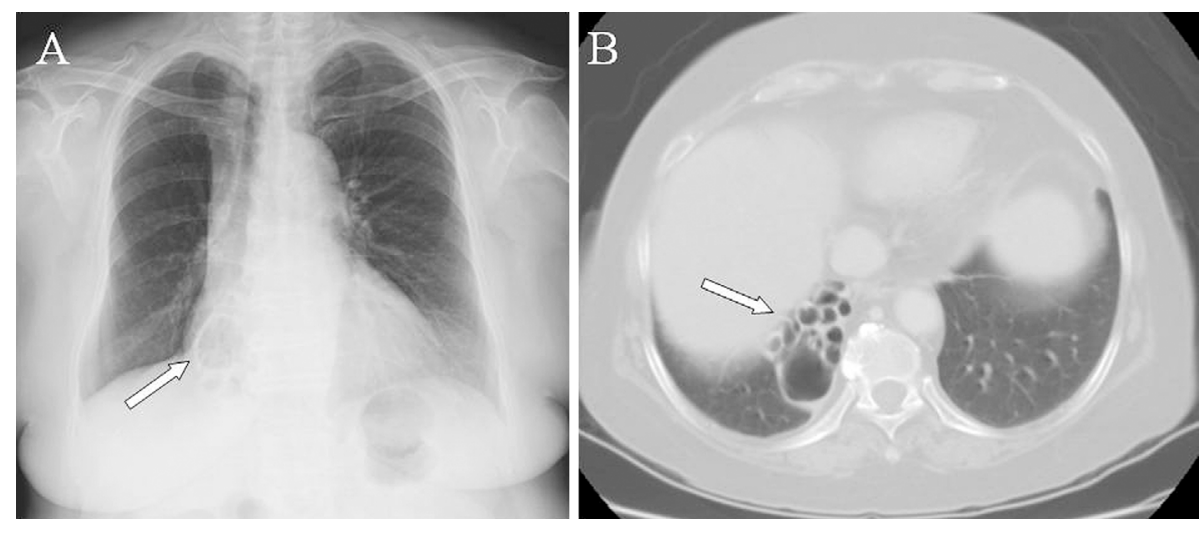

Picture 1.

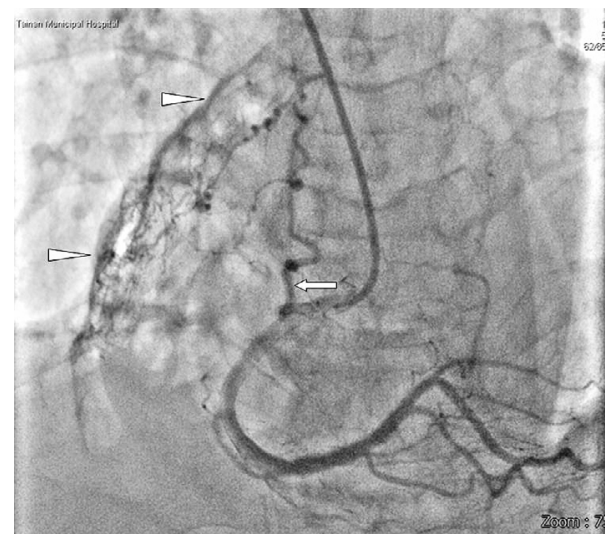

Picture 2.

Pulmonary sequestration is often misdiagnosed as either bronchiectasis or a pulmonary cyst. The arterial supply frequently arises from the thoracic or abdominal aorta, while the blood supply originating from a coronary artery is extremely rare $(1,2)$.

A 77-year-old woman was admitted to our hospital due to unstable angina. Chest radiography revealed a right-lowerlung mass with an air-containing cystic component (Picture $1 \mathrm{~A}$, arrow), which had been similar in size on images taken four years earlier. A previous computed tomography scan showed multiple cystic changes in the right lower lobe (Picture $1 \mathrm{~B}$, arrow). Her coronary angiogram showed insignificant stenosis affecting the coronary arteries. In addition, an anomalous vessel originating from the conus branch of the right coronary artery was noted (Picture 2, arrow) that appeared to supply the right-lower-lung mass (Picture 2, arrowheads), which was suggestive of a pulmonary sequestration. Because the patient was clinically asymptomatic, no intervention was performed. The well-defined margin of the mass indicated that it was most likely an extralobar type of pulmonary sequestration.

The authors state that they have no Conflict of Interest (COI).

\section{References}

1. Hunninghake GM, Kanarek DJ. Pulmonary sequestration supplied 
Intern Med 53: 2553-2554, 2014 DOI: 10.2169/internalmedicine.53.2906

by a coronary artery. Thorax 60: 792, 2005.

2. Silverman ME, White CS, Ziskind AA. Pulmonary sequestration receiving arterial supply from the left circumflex coronary artery. Chest 106: 948-949, 1994.

(C) 2014 The Japanese Society of Internal Medicine http://www.naika.or.jp/imonline/index.html 